https://doi.org/10.36909/jer.v9iICRIE.11663

\title{
Minimum Spillage from Reservoirs using Mixed Integer Linear Programming
}

\author{
Kamel A. Almohseen* \\ College of Engineering -University of Mosul, Iraq ("Professor) \\ e-mail: k.almohseen@uomosul.edu.iq; (Corresponding Author)
}

\begin{abstract}
The use of the traditional linear programming is not possible when an if-condition is to be imposed on the model unless some modifications are made. The difficulty arises due to the fact that the inclusion of if-condition to the generic formulation of the linear programming and its mechanism called "simplex method" is not a trivial task. The mixed integer linear programming seems to be a good candidate to achieve this goal. However, two issues should be satisfied beforehand if one would like to minimize the spill. 1. the reservoir should be full up to the spillway crest level in order for the spillage to occur. 2. the next state of the reservoir after the spill has been occurred should be full as well. Adding binary integer variables to the model helps in achieving the optimal solution in terms of minimum sum of spillage without violating any of the underlying constraints. When the input to the model being altered, the results showed that the model can cope with the uncertainty inherent in any natural inflow process in terms of spillage minimization.
\end{abstract}

Keywords: Optimal Reservoir operation; Mixed Integer Linear Programming; Optimi zation; Water Resources Management 


\section{INTRODUCTION}

There is no doubt that water is the most precious resource that everyone depends on for survival. The optimal use of our limited supply of water has become a central point in planning, operation and management of all water resources projects. The ever growing population of the world and the limited resources of agricultural land and water impose high restrictions on food productivity and availability. Therefore, the proper use of water resources and their reuse has gain popularity in many scientific studies.

Since the 1970s, the water resource management policy has witnessed a shift towards the twin goals viz; improving the efficiency of the operation of the existing water projects and the optimal management of these projects, Wurbs, (1996). While the era of meeting the growing demand by searching for new supplies has become in a wane, nowadays, the operational improvements to the existing projects is seen to be the most preferred course of action. In this regard, the United Nations Organizations concerned with water affairs recommend the urgent need to shift from searching for new projects strategy to optimal management policies for the existing projects FAO, (1995).

The fact that reservoirs are considered the most important component in any water resource system is real, and the needs, requirements and many other factors that affect the operation of reservoir system are inevitably change over time. Consequently, the operating procedures should be reevaluated periodically and adjusted as necessary. The optimal operation of any reservoir system is playing a vital rule in achieving the appropriate use of the limited supply of water. Linear programming (as a method of optimization) has been widely used in the planning and management processes of water resources systems. It is considered to have a specific methodological advantage and is characterized by being an algorithm that can be applied relatively easily Wurbs, (1996). Many engineering problems were represented realistically by 
a linear objective function and a set of linear constraints as well, as these are the perquisite requirements of linear programming. Accordingly, it is possible to say that the linear programming approach is the most applied methodology among other optimization techniques over all the world. However, this technique may sometimes take a backseat in finding the desired solution to some engineering problems, especially when it comes to the existence of a specific conditional state which works only when those conditions are met. For example, and as far as the operating reservoir process is of concern, the release of water through the spillway does not occur unless the reservoir is completely full. Moreover, the state of the reservoir in the next period following the current period must also return full. These two conditions tends to complicate the systematic approach used by linear programming method. So the traditional linear programming technology cannot deal with such sort of problems. Consequently, another kind of solution strategy becomes essential to tackle such type of problems. It has been found that mixed integer linear programming (MILP) is seen to be a good candidate to deal with such obstacle. In MILP, some decision variables can take integer values, while the rest of the other variables can take any real values, that is why it got the name MILP.

The review of literatures reveals that MILP has been extensively applied to a variety of disciplines. As far as the water resources related problems is of concern and for instant, Veintimilla-Reyes et. al.,(2016), applied MILP approach to optimize the Spatio-temporal water allocation problem. They concluded that the use of mixed integer linear programming (MILP) methods can be considered as a good option when there is enough information and the problem to be solved is well known to model each related activity. Additionally, a sensitivity analysis and uncertainty analysis is included in order to determine the most suitable parameters and variables. Again, Veintimilla-Reyes et. al.,(2019), used (MILP) model to simultaneously optimize the allocation of water and the location of one or more new reservoirs; the objective function to be minimized only includes two components (floods and water demand). They concluded that the MILP-model can select the most appropriate locations for 
new reservoirs with a few to optimize the water allocation further while taking investment and management costs into account.

It can be noticed that there is no recent publications concerned the problem of spillage from the

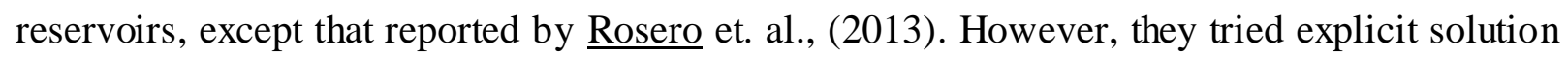
of a Quadratic Program problem by using a geometrical approach. Their work includes a realistic simulation that is intended for illustrating the behavior of the controlled system for reducing the spilling flows.

The current study is an attempt to apply MILP to a hypothetical water reservoir whose optimum storage capacity has already been calculated using traditional linear programming. MILP will be used to find the sum of minimum spillage from this reservoir by imposing the conditions mentioned above.

\section{MODEL FORMULATION}

A previous study, Al-Juboury \& Hachum, (1994) has reported an optimization model which was constructed using linear programming to minimize the storage capacity of "Al-Qiam reservoir on Al-Khosar river joining Tigris river near the center of Mosul city which is still in the planning phase" for a fixed water requirements and a series of monthly inflows into the reservoir.

The model includes the mass balance equations and some other restrictions, as follows:

$$
S_{t+1}=S_{t}+Q_{t}-R_{t}-E_{t}
$$

Where:

$\mathrm{S}_{\mathrm{t}}$ : storage volume of water at the beginning of period $\boldsymbol{t}$ (unknown)

$\mathrm{Q}_{\mathrm{t}}$ : volume of inflow entering the reservoir in period $\boldsymbol{t}$ (known)

$\mathrm{R}_{\mathrm{t}}$ : volume of released water for the downstream requirement in period $\boldsymbol{t}$ (unknown) 
$\mathrm{E}_{\mathrm{t}}$ : volume of evaporation from the reservoir in period $\boldsymbol{t}$ (unknown)

Note: all the above volumes are in million cubic meter

In order to calculate the volume of the monthly evaporation from the reservoir, let $\mathbf{e}_{\mathbf{t}}$ represents the average monthly depth of evaporation, thus:

\section{$\mathbf{E}_{\mathrm{t}}=\mathbf{e}_{\mathrm{t}} *$ Surface Area}

It is clear that the relationship between storage volume and the elevation (a.s.l) from one side, and the surface area of the water in the reservoir and the elevation from other side, are needed to accomplish this goal knowing that they should already available for any reservoir system from the preliminary surveying work. This a third relation can be conducted between the storage and the surface area. Figure (1) below shows this relation for this study.

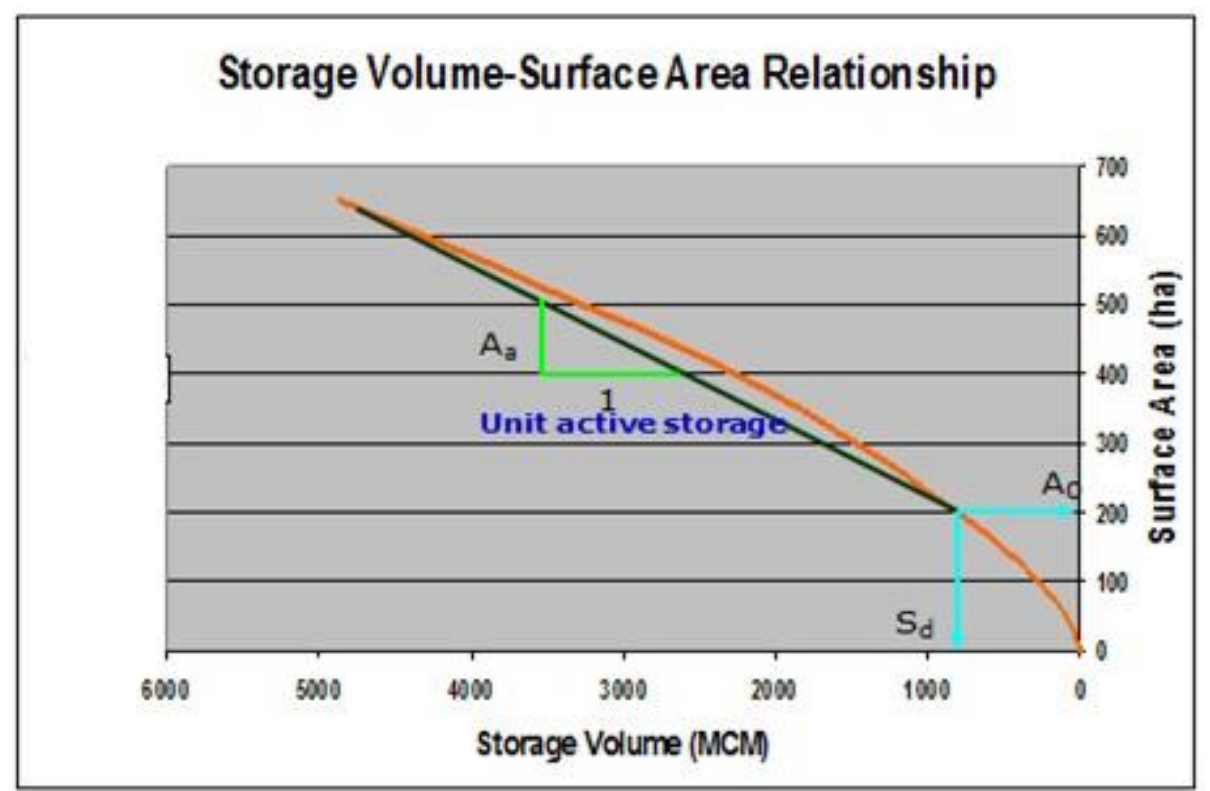

Figure 1. The relationship between storage and surface area of Al-Qiam Reservoir (after Al-Jubouri and Hachum. 1994)

Where:

$\mathbf{A}_{\mathbf{a}}$ : slope of the line approximating the relationship

$\mathbf{A}_{0}$ : fixed surface area corresponding to the dead storage 
$\mathbf{S}_{\mathbf{d}}$ : dead storage

Define $\left(S_{t}+S_{t+1}\right) / 2$ : average storage over the successive periods $t$ and $t+1$

$\mathbf{A}_{\mathbf{a}} *\left(\mathbf{S}_{\mathbf{t}}+\mathbf{S}_{\mathbf{t + 1}}\right) / \mathbf{2}$ : average surface area over the successive periods $\mathbf{t}$ and $\mathbf{t}+\mathbf{1}$

$E_{t}=e_{t}\left\{A a *\left(S_{t}+S_{t+1}\right) / 2+A_{0}\right\}$

$E_{t}=e_{t} A_{a} / 2\left(S_{t}+S_{t+1}\right)+A_{0} e_{t}$

Let $\mathbf{a}_{\mathbf{t}}=\mathbf{e}_{\mathrm{t}} \mathbf{A}_{\mathbf{a}} / \mathbf{2}$

$E_{t}=a_{t} S_{t}+a_{t} S_{t+1}+A_{0} e_{t}$

So equation (1) above can be written;

$S_{t+1}=S_{t}+Q_{t}-R_{t}-a_{t} S_{t}-a_{t} S_{t+1}-A_{0} e_{t}$

$$
\left(1+a_{t}\right) S_{t+1}=\left(1-a_{t}\right) S_{t}+Q_{t}-R_{t}-A_{0} e_{t}
$$

The model can be stated as:

$$
\text { Minimize } \mathrm{K}_{\mathrm{a}}
$$

$\mathbf{K}_{\mathbf{a}}$ is the physical storage capacity of the reservoir

Subject to:

$$
\begin{aligned}
& \mathrm{S}_{\mathrm{t}} \leq \mathrm{K}_{\mathrm{a}} \quad(\mathrm{t}=1,2, \ldots ., \mathrm{T}) \\
& \mathrm{S}_{\mathrm{t}} \geq \mathrm{S}_{\mathrm{d}} \quad(\mathrm{t}=1,2, \ldots ., \mathrm{T})
\end{aligned}
$$

$\mathbf{R}_{\mathbf{t}} \leq$ hydraulic capacity of the channel in the D/S $\quad(t=1,2, \ldots \mathrm{T})$

$\mathbf{R}_{\mathbf{t}} \geq \mathbf{D}_{\mathbf{t}}($ Downstream requirements in period $\mathrm{t})(\mathrm{t}=1,2, \ldots ., \mathrm{T})$

$$
\sum \mathrm{R}_{\mathrm{t}} \leq \sum \mathrm{Q}_{\mathrm{t}},(\mathrm{t}=1,2, \ldots, \mathrm{T})
$$


The above model leans itself for the solution by any standard linear programming software, because the variables in the objective function and the constraints are all linear.

\section{RESERVOIR OPERATION}

The formulation given in equations (1 through 8 ) above is considered typical for calculating the active storage volume of the water reservoir when the inflows data into the reservoir and the water requirements for the downstream are available and this is specifically useful in the planning and design stages. As far as the reservoir operation process is of concern, it requires to fulfilling the downstream requirements at any period of time and this can be achieved by imposing an appropriate constraint, however, the objective function would be the minimization of the water losses over the spillway especially in the wet season. Back to the traditional linear programming model represented by the equations (1 to 8 ), two if-conditions must be satisfied if one would like to get the optimal solution. Those conditions are:

1. No spill could occur at any period of the reservoir operation unless the reservoir is full of water.

2. The reservoir must have considered full in the period following the current period.

Mathematically; The new model formulation becomes:

$$
\text { Minimize } \sum \mathrm{Sp}_{\mathrm{t}}
$$

Where: $\mathbf{S} \mathbf{p}_{\mathbf{t}}$ is the volume of water spill over the spillway at $(\mathbf{t}=\mathbf{1}, \mathbf{2}, \ldots . ., \mathbf{T})$.

Subject to the following constraints;

$$
\left(1+a_{t}\right) S_{t+1}=\left(1-a_{t}\right) S_{t}+Q_{t}-R_{t}-A_{0} e_{t}-S p_{t}
$$

and the constraints given in $(4,5,6,7,8)$. 
Adding a new integer binary decision variable( $\left.\mathrm{y}_{\mathrm{t}}\right)$ which will cope with the two conditions aforementioned. To guarantee those conditions two new constraints have been imposed as follow:

$$
\begin{gathered}
\mathrm{y}_{\mathrm{t}} \leq \mathrm{S}_{\mathrm{t}+1} / \mathrm{K}_{\mathrm{a}} \\
0 \leq \mathrm{y}_{\mathrm{t}} \leq 1, \text { (integer) }
\end{gathered}
$$

The model needed an extra cons traint to insure that the spill water does not exceed the physical capacity of the spillway;

$$
\mathrm{Sp}_{\mathrm{t}} \leq \mathrm{M}^{*} \mathrm{y}_{\mathrm{t}}
$$

Where $\mathbf{M}$ is relatively large number say (1000).

Also constraint (8) above needs to be modified to include the spill water to insure that the constraint of mass conservation is hold such that:

$$
\sum \mathrm{R}_{\mathrm{t}}+\mathrm{Sp}_{\mathrm{t}} \leq \sum \mathrm{Q}_{\mathrm{t}},(\mathrm{t}=1,2, \ldots, \mathrm{T})
$$

It should be mentioned that the new MILP model cannot calculate the optimum storage capacity $\mathrm{K}_{\mathrm{a}}$ for a known release, Vedulas \& Mujumdar (2016), as it could be done by the traditional linear programming such as the study conducted by Al-Juboury \& Hachum, (1994) and mentioned above. This is because the constraint given in equation (11) above will be in the form $\mathrm{y}_{\mathrm{t}} \cdot \mathrm{Ka} \leq \mathrm{S}_{\mathrm{t}+1}$ which is a nonlinear relation and clearly is beyond the capability of the linear programming technique. 


\section{AL-QAIM RESERVOIR (CASE STUDY)}

The proposed Al-Qiam reservoir on the Al-Khosar River was selected for the purpose of applying the proposed mathematical model to determine the applicability of the model in deriving an optimal operation policy for a single reservoir system. Al Khosar River is one of the seasonal tributaries join the left bank of Tigris River near the center of Mosul city.

Al-Qaim reservoir is located $18 \mathrm{~km}$ north of the city of Mosul, with catchment area of approximately $640 \mathrm{~km}$, Sogreah, (1982).

The absence of discharge gauging stations on Al-Khosar river made it necessary to adopt the similarity method (usually used by hydrologists) between this basin and the adjacent basin called Al-Khazir river basin, as the later has a relatively credible records of discharge data for many years, Sogreah, (1982). The monthly data for the inflow to the Al-Qaim reservoir was extracted based on the data available for the Al-Khazir river station at Manquba. Table-1, lists the average monthly flow volume entering Al-Qaim reservoir.

\section{OPTIMAL STORAGE CAPACITY FOR AL-QIAM RSERVOIR}

According to Al-Juboury \& Hachum, (1994), the traditional linear programming has been applied to calculate the optimal storage capacity of Al-Qiam reservoir. The data used to run the model is shown in Table (1). The result of the model reveals that the optimal total storage is around $39 \mathrm{MCM}$ consisting of $22 \mathrm{MCM}$ which devoted to the dead storage and $17 \mathrm{MCM}$ as an active storage. Thus, $39 \mathrm{MCM}$ is the total storage capacity of Al-Qiam reservoir.

Table 1 Average monthly Inflow volume, downstream requirements and evaporation used for calculating the optimal storage capacity of Al-Qaim reservoir 


\begin{tabular}{|c|c|c|c|}
\hline Month & $\begin{array}{c}\text { Monthly Average Inflow } \\
\text { Volume } \\
(\mathrm{MCM})\end{array}$ & $\begin{array}{c}\text { Downstream } \\
\text { Requirements } \\
\text { (MCM) }\end{array}$ & $\begin{array}{c}\text { Evaporation } \\
\text { (mm/month) }\end{array}$ \\
\hline January & 15.940 & 0.264 & 30 \\
\hline February & 25.100 & 1.712 & 40 \\
\hline March & 31.620 & 3.512 & 116 \\
\hline April & 26.180 & 6.602 & 218 \\
\hline May & 13.220 & 5 & 340 \\
\hline June & 5.780 & 7.072 & 340 \\
\hline July & 4.330 & 6.492 & 218 \\
\hline August & 3.810 & 4.74 & 52 \\
\hline September & 3.680 & 3.884 & 30 \\
\hline October & 4.250 & 2.456 & \\
\hline November & 6.430 & 1.376 & 0.088 \\
\hline December & 12.830 & & \\
\hline Total & $\mathbf{1 5 3 . 1 7 0}$ & & \\
\hline
\end{tabular}

Figure (2) below, shows the optimal operating policy of Al-Qiam reservoir which leads to the minimum storage $\mathrm{K}_{\mathrm{a}}$. The solution has been reproduced here for the study given by Al-Juboury \& Hachum, (1994) using the traditional linear programming technique.

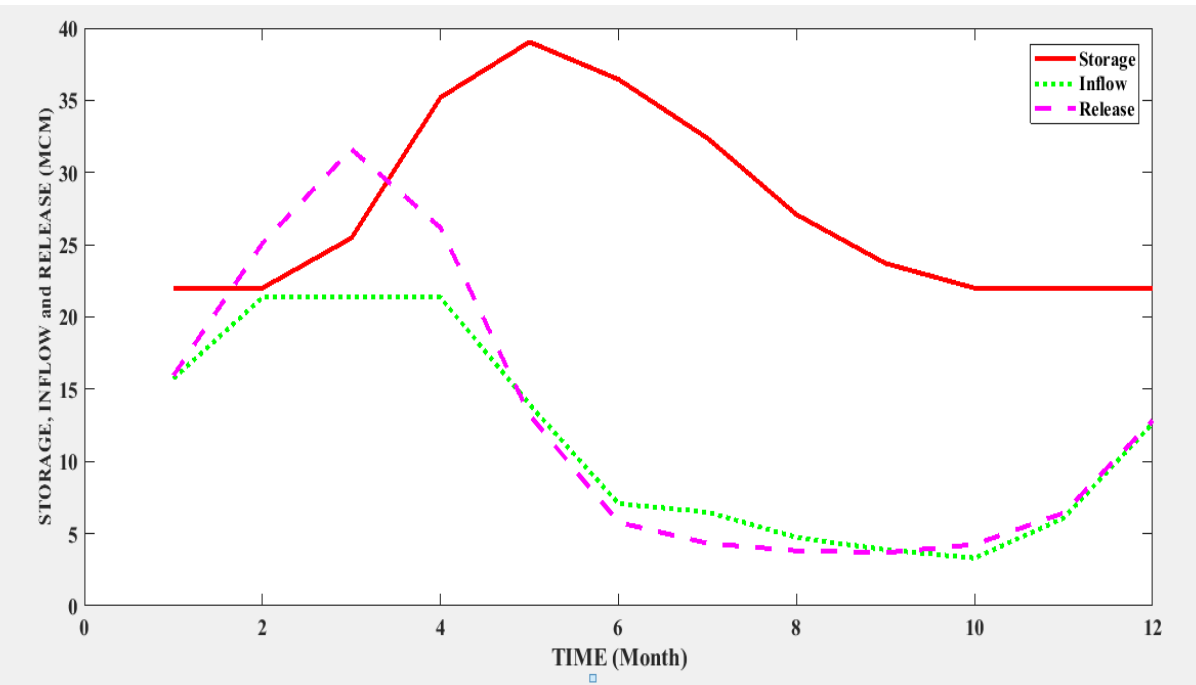

Figure 2 The optimal operating policy with minimum storage capacity of Al-Qiam reservoir using traditional Linear Programming Model. (After Al-Jubouri\&Hachum,1994) 


\section{APPLICATION OF MILP MODEL}

Mixed Integer Linear Programming Model (equations 9 through 14) has been applied using large scale linear programming tool available in MATLAB platform with the same data and a storage capacity of $39 \mathrm{MCM}$. The model was satisfactorily calculating the spillage from the reservoir. Thus, MILP has succeeded in the inclusion of the spill process in which the previous model i.e. traditional linear programming has failed to achieve. The optimal operating policy in terms of storage profile, releases trajectory and spillage pattern have been depicted in figure (3) in addition to the monthly average inflow series.

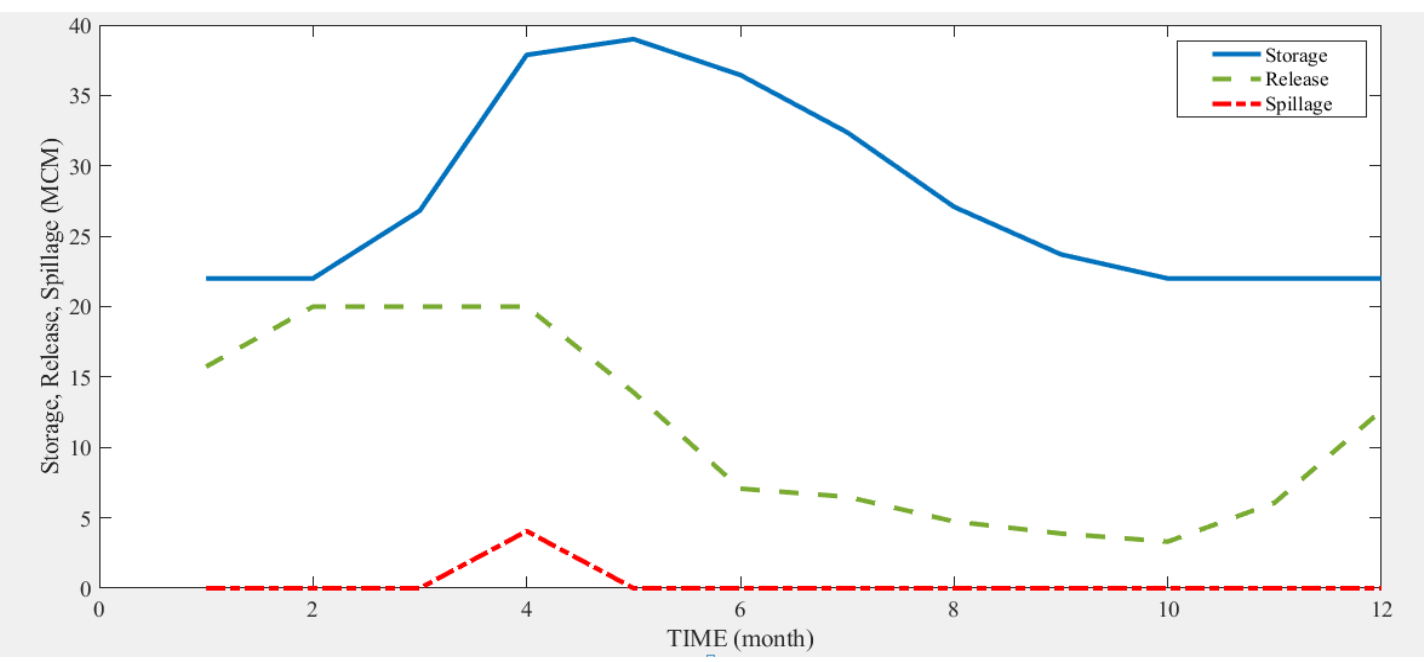

Figure 3 Storage, Release, Spillage Trajectories for average inflow corresponding to optimal operating policy (Spillage Minimization) using MILP Model.

\section{RESULTS AND DISCUSSION}

Comparison between Figure (2) and Figure (3) indicates that they are different in sense figure (2) does not refer to the spill though it is one of the main components of the mass balance equation. Apparently, the model could not cope with conditions involved in the process of the spillage calculations. However, MILP was able to do the job successfully. Additionally, and in order to confirm the flexibility of the proposed model in calculating the resulting spillage when the input to the model is deviated from the average inflows, two extra runs have been 
conducted as a base of comparison measure. Firstly, the average inflow is increased by $25 \%$ and the model is run again. The results of the optimal solution in terms of storage, release and spillage trajectories is shown in figure (4) below. It is obvious that the total spill has been increased accordingly.

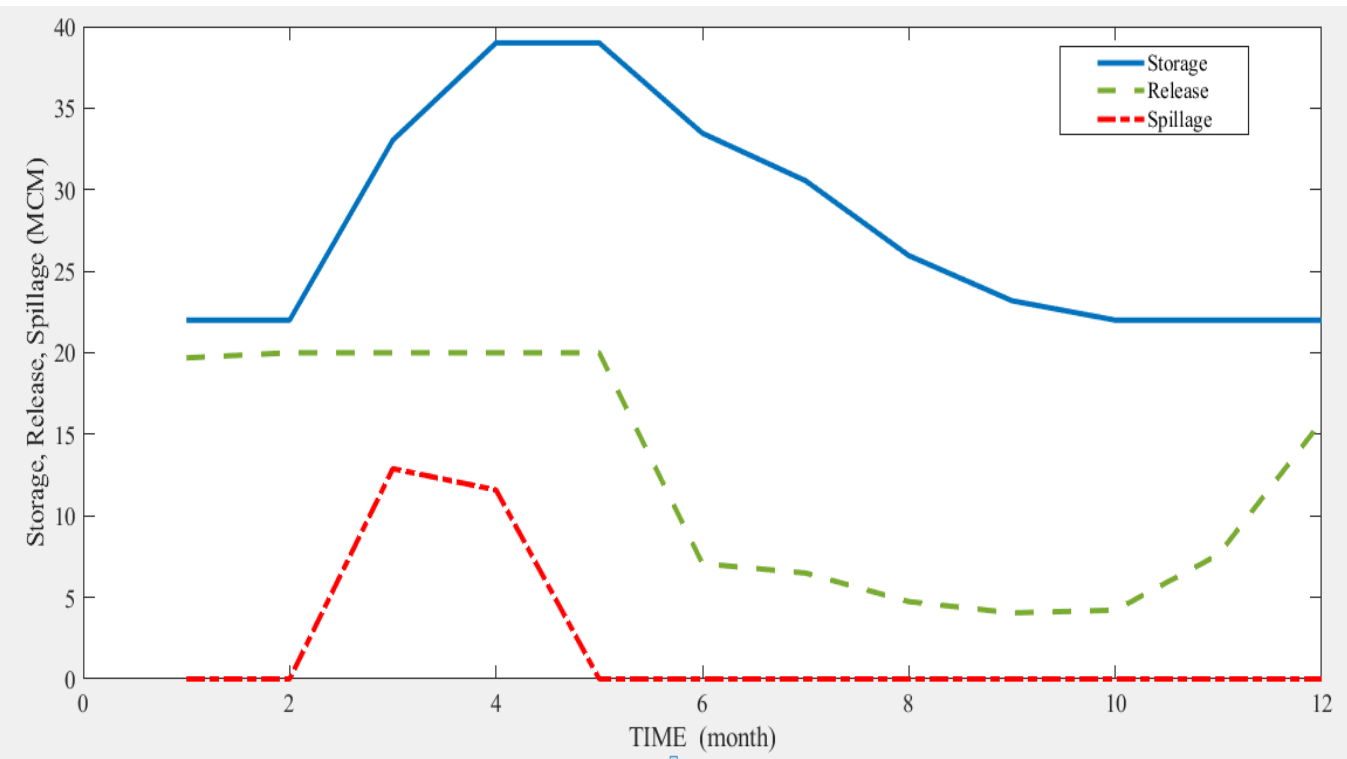

Figure 4: Storage, Release, Spillage Trajectories for $25 \%$ increased average inflow corresponding to optimal operating policy (Spillage Minimization).

Secondly, and for further confirmation, the average inflow was increased by $50 \%$, and the result is shown in figure (5) below.

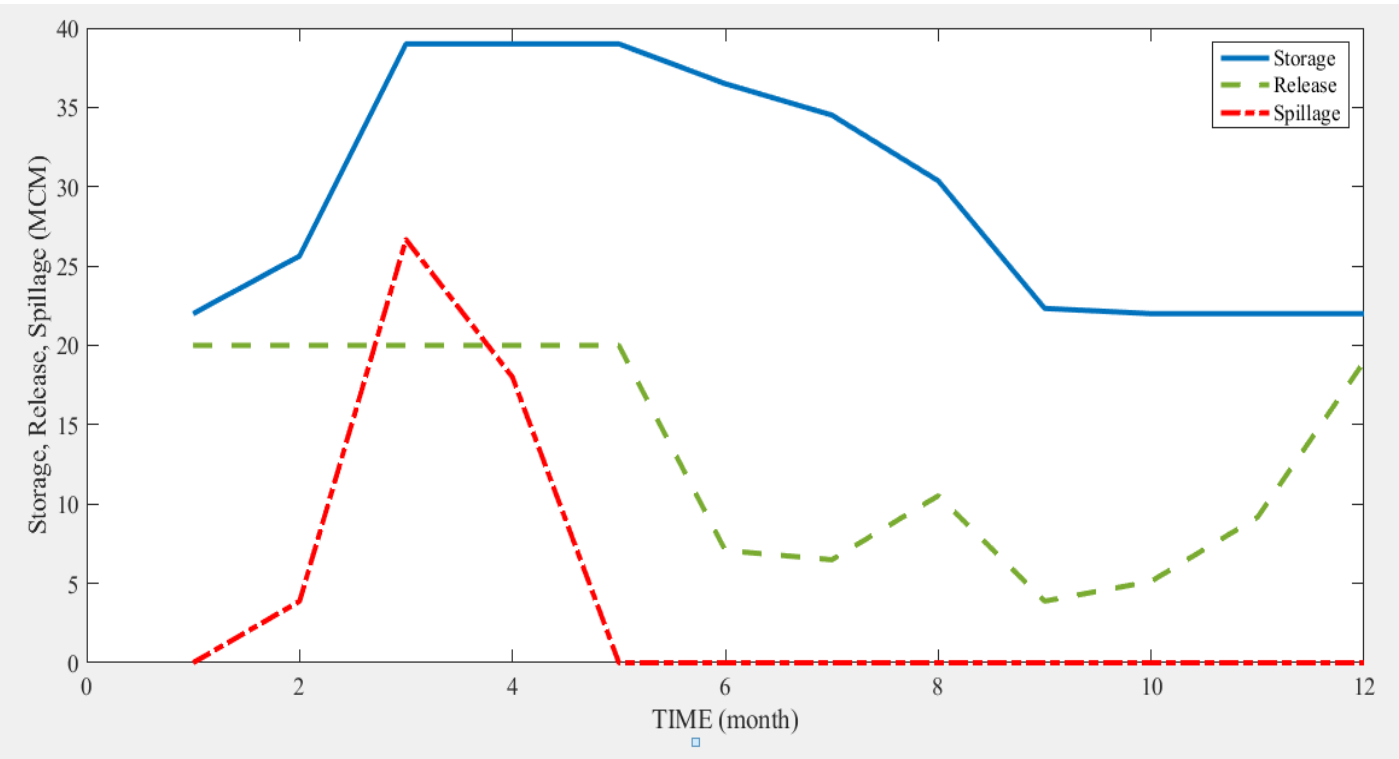


Figure 5: Storage, Release, Spillage Trajectories for 50\% increased average inflow corresponding to optimal operating policy (Spillage Minimization).

The results indicate that when the releases from other outlets of the reservoir rather than the spillway, were considered as an objective function to be maximized, it leads to exactly the same results obtained from the minimization of the spill from the reservoir. In such case, more land could be irrigated and/or power generation might be increased, while at the same time the minimum spill is also guaranteed.

\section{CONCLUSION}

The current study showed the possibility of using MILP model to minimize the spill from the spillway of the reservoir which is very important aspect in the operation process of any reservoir system, otherwise substantial amount of water could be lost over the spillway especially during the wet season. However, the calculation of these spill was not possible using the traditional linear programming method due to the exist of if-conditions which must be satisfied and included in the formulation of the model. Consequently, MILP is shown to be able to cope with such difficulty. Additionally, and to introduce a measure of comparison and confirming the flexibility of the proposed model, the input to the model has been altered, yet the results emerged reveal that the model can cope quite satisfactory with uncertainty in the inflow entering the reservoir which is considered an inherent property of any natural inflow process. The results are also indicates that if the objective function was altered to the maximization of the releases from the reservoir, the same optimal operating policy could be achieved and some additional benefits could be accrued. 


\section{REFERENCES}

Al-Jubouri, K. and A. Hachum, 1994. The Optimal Capacity of Reservoir. Second Engineering Conference, Military College of Engineering, Baghdad.

Al-Mohseen, K. A. \& A. R. M Twafiiq, 2014. Stochastic Dynamic Programming Model for Single Reservoir System Operation (Case Study). Al-Rafidain Engineering Journal, vol. 22, No. 1, University of Mosul, Iraq.

FAO, 1995. Reforming Water Resources Policy - A guide to methods, processes and practices. Irrigation and Drainage Paper no. 52.

Loucks DP, J.R. Stedinger\& D.A. Haith. Water resources systems planning and analyses. Printice-Hall, New Jersey.1981.

Nadia Rosero; José M. Ramirez; John J. Martinez. Minimization of water losses for optimal hydroelectric power generation. 21st Mediterranean Conference on Control and Automation. 25-28 June 2013 . Published: IEEE. DOI: 10.1109/MED.2013.6608891

Sogreah Consulting Engineer. Al-Qaim Dam Planning Report. Ministry of Irrigation, General Establishment of Studies and Designs. 1982.

Vedulas S. \& P. P. Mujumdar. Water Resources Systems: Modelling Techniques and Analysis. India. 2016.

Veintimilla-Reyes, J.; Cattrysse, D.; De Meyer, A.; Van Orshoven, J. Mixed Integer Linear Programming (MILP) approach to deal with spatio-temporal water allocation. In Proceedings of the 2nd EWaS International Conference: "Efficient \& Sustainable Water Systems Management toward Worth Living Development", Chania, Crete, Greece, 1-4 July 2016; pp

Veintimilla-Reyes, J.,Annelies De Meyer, Dirk Cattrysse,Eduardo Tacuri, Pablo Vanegas Felipe Cisnerosand Jos Van Orshoven._MILP for Optimizing Water Allocation and Reservoir Location: A Case Study for the Machángara River Basin, Ecuador. Water 2019, 11(5), 1011; https://doi.org/10.3390/w11051011

Wurbs, R. A. Modeling and Analysis of Reservoir System Operation. Prentice Hall PTR, Prentice-Hall Inc., NJ. 1996. 